\title{
The Adoption of Wearables for a Healthy Lifestyle: Can Gamification Help?
}

Ton Spil, a.a.m.spil@utwente.nl, University of Twente, The Netherlands

Ali Sunyaev, University of Cologne, Germany

Scott Thiebes, University of Cologne, Germany

Rolf van Baalen, University of Twente, The Netherlands

\begin{abstract}
Wearables are a novel device category that promotes healthy lifestyles, providing consumers with unforeseen health monitoring capabilities. Gamification, on the other hand, is an intriguing phenomenon that seeks to motivate people by applying game design elements to non-gaming contexts like healthcare. While increasing literature is available on wearables in healthcare and gamification in healthcare, thus far, little attention has been paid to the combination of both concepts. In this paper we take a first step towards closing this gap by looking at how gamification of health apps can provide consumers with a motivating and enticing interaction concept to drive the adoption of wearables for a healthy lifestyle. Thereby, we apply a technological and consumer market lens and analyze rich data from 40 interviews and an online survey. Our results highlight that although people show high interest in wearables and gamification, their combined added value is still unknown among potential consumers. A practical contribution of this paper is that industry should make the functionality and relevance much more clear. Activity tracking and fitness \& health functionality are perceived as most important by (potential) consumers.
\end{abstract}

\section{Introduction}

"We are getting to an infliction point in healthcare" [1]. Chronic diseases are a major cause of death worldwide [2]. They usually result from unhealthy habits and lifestyles, including physical inactivity and an unhealthy diet. Not only do chronic diseases severely impact people's lives due to, for example, the need of continuous medication, they are also a major driver of the overall expenses of healthcare systems around the world. To improve quality of live and reduce the cost of healthcare systems effective ways to achieve and maintain healthier lifestyles are required.

Drawing from the fact that usage of smartphones is high, read in combination with the enormous popularity of app downloads, the use of apps to promote healthy lifestyles seems obvious and might have great potential to promote changes in behavior towards a healthy lifestyle as well [3]. Worldwide, the number of smartphones exceeded the world population in 2014 [4]. Within the next three years there will presumably be 1.5 smartphones per capita, which means that in 201911.5 billion mobile connected devices are spread among the world population. Wearables (e.g., smart watches; cf. section 2.1) directly build on the success of smartphones, offering extensive health-related functionality usually not found in smartphones and other mobile devices (e.g., the ability to collect physical body data like heart rates) $[6,12]$. While the functionality of health related software applications (i.e., health and fitness apps) on smartphones is already quite impressive today, wearables have the potential to further enhance this trend due to manufacturers of wearable devices massively focusing on health monitoring and the promotion of healthy lifestyles. Yet, despite wearables offering unforeseen capabilities for supporting a healthier lifestyle, market adoption of wearables is still considerable low. To date the hype around wearables is not yet reflected by consumers' adoption of wearable devices.

Gamification presents itself as a novel approach that seeks to inherently motivate people [5]. As such, the healthcare domain has experienced a rapid growth of gamification and gamified health and fitness apps (further on simply referred to as gamified health apps) to motivate people living a healthier life over the past few years. Nowadays, gamified health apps take various forms, ranging from smoke cessation to asthma management [6]. Adding to this, gamified health apps such as RunKeeper, MyFitnessPal, and Nike+ Running, are built-in with GPS, social networking capabilities (e.g., sharing on Facebook and Twitter), and sophisticated sensor technologies that provide details of physiological data such as calories burnt, heart rate, blood glucose level and blood pressure. They thus, have the potential to improve the effectiveness and cost of health interventions [7, 8] and present an ideal companion for wearables, that provides a motivating and enticing interaction concept.

Altogether, the emergence of technology that promotes healthy lifestyles (e.g., wearables and gamified health apps) may offer effective means for encouraging people to adopt healthy behaviors and lead to an overall healthier population. Albeit, little is known about the how well wearables and gamified health apps play together and whether or not gamification can drive the adoption of wearables for healthier lifestyles. Therefore, the research question addressed in this paper is as follows:

RQ: To what extent does gamification influence the market adoption process of wearable devices? 
Literature on both, wearables in healthcare and gamification in healthcare is increasingly being published in highly ranked journals and conference proceedings. However, to date little is known about the combination of both aspects and how well they play together. With this research we take a first step towards shedding light into the black box that is the combination of adopting wearables for a healthy lifestyle and gamified health apps, thus seeking to close this obvious gap in the literature. Therefore, we collected an extensive dataset by conducting interviews with 40 residents from the Netherlands and Germany as well as an online survey among 56 participants.

This study contributes to research and practice. For research we are one of the first to take a deeper look into the novel field of gamification of health apps for wearable devices. Based on a multi-method analysis of an extensive dataset (including a Technology Acceptance Model (TAM) perspective [9]) we provide rich insights into customers' perceptions of gamification of health apps and wearables, which may serve as a foundation for future studies on this timely and unique phenomenon. For practice we provide evidence that customers are highly interested in wearables and gamification but lack knowledge about their combined added value. We also present gamification as a promising approach to drive the adoption of wearables for the promotion of healthy lifestyles.

This paper proceeds as follows. The next section provides an overview of related work, including conceptualizations of wearables and gamification. In section three we outline our research approach. Section four presents descriptive results of our research, while we discuss our results in chapter five. The paper is concluded with chapter six.

\section{Related Work}

\subsection{What are Wearables?}

Wearables are a booming device category with shipments of wearables being expected to grow from 9.7 million devices in 2013 to 135 million devices in 2018 [10]. Thereby, the terms "wearables", "wearable devices", and "wearable technology" are all synonyms referring to "electronic technologies or computers that are incorporated into items of clothing and accessories which can comfortably be worn on the body" [11]. Wearables exist in various form factors, which are often re-iterations of already existing devices like watches (e.g., Apple Watch and Samsung Gear S2), glasses (e.g., Google Glass), and bracelets (e.g., Fitbit Flex and Jawbone UP). In general, wearables have some form of communications capability and will allow the wearer access to collected information in real-time. Data-input capabilities are also a feature of such devices, as is local storage. Common functionalities of wearables include step counting, distance and speed tracking, heart rate monitoring, and communication with other devices like smartphones via Bluetooth or Wi-Fi (cf. table 1).

The implications and uses of wearables are far reaching and can influence the fields of health and medicine, fitness, aging, disabilities, education, transportation, enterprise, finance, gaming, and music. Wearables can perform many of the same computing tasks as mobile phones and laptop computers [11]. However, in some cases, wearables can outperform these hand-held devices entirely. Wearables tend to be more sophisticated than hand-held technology on the market today in that they can provide sensory and scanning features not typically seen in mobile and laptop devices, such as biofeedback and tracking of physiological function. These functionalities becoming available to the mainstream market lead to an array of new possibilities and functionalities. When thinking about applications for wearables, the collection of movement and heart rate data is very straightforward [12]. As such, wearables could be a significant boon to mHealth technologies [13]. In the future, wearables could host more bio-sensors and take more accurate measurements than the simple accelerometer-based wristbands and smartphones. These wearables are interesting because they enhance functionality of existing technologies. This is mainly due to the fact that wearables are something you wear, which means that it can collect personal physical information throughout the day. Overall, the challenge of wearables in each area of application will be to smoothly incorporate functional, portable electronics and computers into individuals' daily lives, [11] especially in healthcare.

Tab. 1: Technologies, measurements, and data/ functions in wearables adapted from $[7,14]$.

\begin{tabular}{|l|l|l|}
\hline Technology & Measurements & Data/function \\
\hline Pedometer & $\begin{array}{l}\text { Step counting, } \\
\text { distance estimation }\end{array}$ & $\begin{array}{l}\text { Distance + speed } \\
\text { tracking, calorie } \\
\text { counting }\end{array}$ \\
\hline GPS & $\begin{array}{l}\text { Distance tracking, } \\
\text { speed tracking, } \\
\text { mode of movement }\end{array}$ & $\begin{array}{l}\text { Distance + speed } \\
\text { tracking, recording } \\
\text { achievements }\end{array}$ \\
\hline Accelerometer & Speed tracking & Speed tracking \\
\hline meart rate & $\begin{array}{l}\text { Heart rate } \\
\text { monitoring, } \\
\text { Energy } \\
\text { Expenditure }\end{array}$ & $\begin{array}{l}\text { Heartbeat } \\
\text { measuring + calorie } \\
\text { counting }\end{array}$ \\
\hline Bluetooth & $\begin{array}{l}\text { Interconnects } \\
\text { devices }\end{array}$ & $\begin{array}{l}\text { Sharing capability } \\
+ \text { expandability }\end{array}$ \\
\hline Wi-Fi & $\begin{array}{l}\text { Networking } \\
\text { capability, location } \\
\text { estimation }\end{array}$ & $\begin{array}{l}\text { Sharing capability } \\
+ \text { expandability }\end{array}$ \\
\hline
\end{tabular}




\subsection{What is Gamification?}

Gamification is a novel concept that, in its broadest sense, refers to the use of "game design elements in nongame contexts" [5]. Based on people's growing passion for videogames and the increasing pervasiveness of technology in form of smartphones, wearables, and apps, gamification aims at changing people's behavior by applying game design elements to non-game situations to reinforce desired behavioral traits [15]. Thus, gamification has the potential inherently motivate people and to make non-gaming applications like repetitive and tiresome everyday tasks (e.g., taking medication every day) more engaging and enjoyable $[16,17]$.

Concepts related to but different from gamification include pervasive games and serious games. Pervasive games extend beyond the borders of traditional videogames in a spatial, temporal or social manner [18], while serious games are full-grown games for purposes other than entertainment (e.g., education or workforce training) [5]. Whereas both concepts, pervasive and serious games, rely on full-grown games, gamification focuses on the use of game design elements only, to create so-called gameful experiences. Thereby, extant research distinguishes two basic types of game design elements for gamification [19, 20]. First, game mechanics are functional components also found in traditional videogames (e.g., point systems, leaderboards, or badges) that stimulate and support user interaction [21]. Second, game dynamics are the reactions of individuals, which are caused by employed game mechanics [20]. They seek to satisfy basic human needs and desires like, for instance, the desires for reward and self-expression. Together, game mechanics and game dynamics can be employed to create gameful experiences that inherently motivate people and thus can be used to regulate people's long-term behavior.

Gamification has been researched and applied in various domains, including education, finance, workplace settings, and healthcare [20]. Due to its potential to change people's behavior through an adequate and carefully chosen combination of game mechanics and game dynamics, gamification is of particular interest from an information systems and health IT perspective. Especially in healthcare, increasing attention is being paid to gamification to, for example, increase people's motivation to adopt a healthy lifestyle [16] or to support people with chronic diseases in managing their disease [6]. A detailed overview of gamified health apps is, for example, provided by [22]. In general, application of gamification in healthcare settings bears potentials to improve overall health by effective disease management and a way to counteract the surging costs of healthcare systems around the world.

However, the majority of studies that investigate gamification, especially in healthcare settings, focus on webbased or smartphone apps. Thus far, we lack knowledge on how to integrate gamification and wearable devices in a meaningful way and the effects that gamification has on the wearables industry in general. With this paper we seek to make a first step towards closing this gap by looking at how gamification affects the market adoption of wearable devices.

\section{Research Approach}

For this study we employed a multi-method research approach composed of three consecutive steps in order to investigate gamification's potential to drive the adoption of wearables for healthier lifestyles. First, we conducted PRIMA-interviews [23] among forty (40) residents of mainly the Netherlands and Germany to get insight into current customer perceptions on gamification. Interviewees came from diverse backgrounds and were aged between 15 and 55. The PRIMA model[23] is derived from well-known methods like TAM [9] and DOI [25]. During the interviews we queried interviewees on their opinions and usages of gamified apps. For analysis of the interviews we adopted the coding process by [24]. They divide qualitative data analysis into three different procedures: Data reduction, data display, and conclusion drawing/verification. For the data reduction phase, coding was chosen because it provides a good overview of the answers given by respondents and their opinions on various aspects. The coding was based on the process described by [24], who state that: "Codes are tags or labels for assigning units of meaning to the descriptive or inferential information compiled during a study. Codes are usually attached to 'chunks' of varying size - words, phrases, sentences or whole paragraphs." Therefore, responses obtained from the interviews were assigned one of five tags, ranging from very positive (++) to very negative (-). For data display, the available data has been statistically processed in Microsoft Office Excel to generate an insight into the responses, next to that this program made graphical presentation possible.

Second, we performed an extensive literature review to identify potential advantages of wearable devices for promoting health lifestyles as well as gamification of health apps.

To find out how willing people are to adopt new technologies, it is important to acknowledge the market adoption process. To place this data in perspective, some well-known theories and models have been used. These models are the Diffusion of Innovations by [25], the TAM by [9] and the Product Life Cycle model by [26].

Third, following the interviews we conducted an online survey questions based on the Kano model (see appendix)[27]. Fifty-six (56) respondents from Germany, The Netherlands and the United Kingdom answered the questions on which a thorough analysis was possible. Twenty-nine were female, twenty-seven male in the age of 18-66. The respondents had the opportunity to watch several small guide movies of wearables and gamification during the questionnaire if they needed more understanding. The Kano 
Model of Customer Satisfaction classifies product attributes based on how they are perceived by customers and their effect on customer satisfaction [27]. This method distinguishes five different classifications in product attributes: Must-be, One-dimensional, Attractive, Indifferent and Reverse requirements. This method of questioning and analyzing creates an insight in the way potential customers perceive wearable products and gamified applications for these devices. It provides more information on the requirements for wearables and the role gamification can play in that process. Because of the fact that wearables exist in different assemblies it is important to find out which functions are desired by potential customers. Therefore we did not use TAM [9] as a causal model but with a Pearson analysis more as an explanatory tool within the Kano model and the PRIMA model.

We used the knowledge gained from this analysis as a generalization and connected it to the qualitative information on gamification gained from the interviews. By making this connection, we were able to investigate the impact of gamification on the future success of wearables.

\section{Descriptive Results}

\subsection{Adoption of Gamification}

When looking at personal opinions on gamification, data gained from 40 interviews based on the PRIMA method comes in useful. These interviews have been conducted among a widespread array of respondents. More information on the data gathering process can be found in section 3 . In the interviews, the opinions on the use of gamification have been queried. The relevant results are presented in figure 2 below.

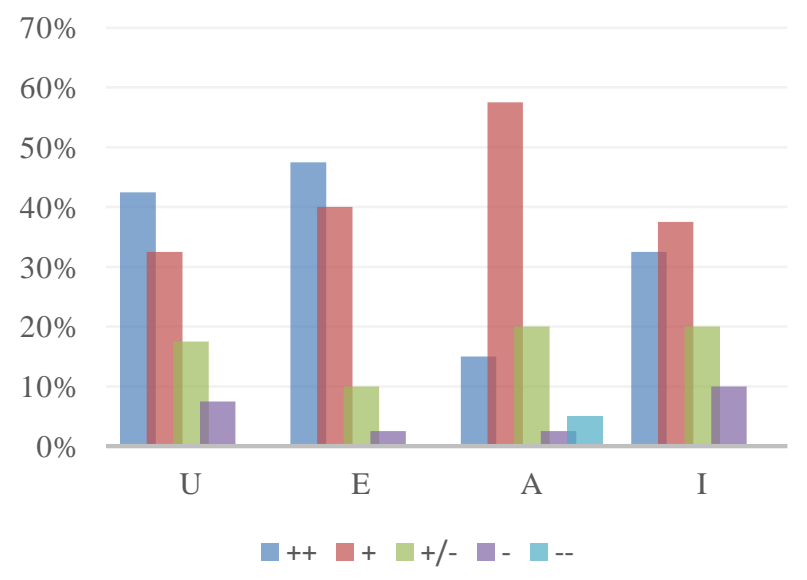

Fig. 2: TAM analysis on gamification.

For the factors Usefulness (U), Ease of Use (E), Attitude (A) and Intention of Use (I), the interviews give a clear insight. What we see from this data is that people in general are very willing to adopt gamification. The total of positive reactions for all the different model factors is above $70 \%$. These numbers show that most people have confidence in gamification.

What we see very clearly in this graph is that respondents have a positive opinion on the relevance of gamification for improving their personal health. Next to that, respondents are confident in the user-friendliness of gamification. The attitude towards gamification is predominantly positive and this has a great effect on the willingness of people to use gamification in their everyday life.

The factors $U$ and $E$ deserve some extra notice, since the answers from the interviews show that people have a lot of confidence in both the Perceived Usefulness as well as the user-friendliness of gamification. This is probably caused by the added functionality and user-friendliness apps on their smartphones offer since most people associate gamification with a mobile app, played on their smartphone.

When looking at the actual usage of fitness apps, the questionnaire provides additional data. When asked about the usage of fitness and running apps, the response is quite two-sided. Currently $47 \%$ of the respondents are using one or more fitness apps. On the other hand, 53\% states that they are not using apps like these. $26 \%$ of the respondents claim however that they are willing to use these in the future. This shows that fitness apps have been widely adopted, although not to a degree that sets an industry standard. The willingness towards adoption is very clear however, which will obviously lead to a wider spread adoption of this technology. When looking at the Product Life Cycle, gamification can be considered as a growing phenomenon, which will become bigger.

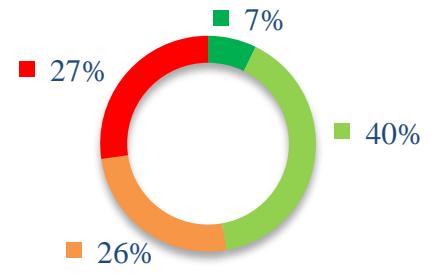

- Yes, i am currently using multiple apps like this

Yes, i am currently using a single app like this

I am not using an app like this currently but want to do this in the future

- No, i am currently not using an app like this and do not plan to do so in the future

Fig. 3: Gamified health app usage.

When looking at Roger's Diffusion of Innovation curve, the adoption of gamified health apps is approximately in the late early majority. Therefore the late majority and laggards should still be convinced. The data gained from the interviews show promise on this point, since $75 \%$ of 
respondents perceive these apps as useful. Following from this data, $73 \%$ of respondents claims they have the intention to use these apps. This data shows the massive potential market of these applications. Considering the huge size of this market currently, it provides a good basis for industries that are related to the gamified health app industry.

\subsection{Adoption of Wearables}

When looking at the product life cycle [26], it is clear that smartphones have become mature. As shown before in this thesis, the massive success of the smartphone industry heavily influences the development of new applications and therewith also the introduction of gamification for individuals. Market data has shown that gamified health apps are quickly becoming a success over the last few years. Next to that, data by Flurry Analytics shows that fitness apps are used way more on a daily basis than other apps [28].

The success and growth of gamification apps, especially with health and fitness functionalities together with the development of new technologies and the growing ability to equip small devices with new technology for the mainstream market lead to a new group of products which can be worn [12] in which the tech world is creating a future of wearable devices. They promise to entertain consumers and help in adopting a healthier lifestyle.

Technology companies' interests in health and wellness have sparked the creation of a myriad of wearable devices, from fitness bands that monitor activity and sleep patterns to flexible patches that can detect movement, body temperature, heart rate, hydration level and more. These devices produce data that, often enabled with analytics, can be used by consumers to manage their health and by healthcare organizations to improve care and potentially reduce costs through systems such as remote patient monitoring. Data generated by personal devices can be used by insurers and employers to better manage health, wellness and Introduction healthcare costs, and by pharmaceutical and life sciences companies to run more robust clinical trials and capture data to support outcomes-based reimbursement. Many consumers believe wearables can improve their health [29].

To find out whether these statements are true and which functions are really desired by the potential market a questionnaire study has been carried out. At first, the opinion of potential customers towards wearable devices has been researched. This study is based on the TAM-model by [9] in an explanatory way, not in a causal way.

When looking at the TAM analysis conducted in the questionnaire, several observations can be made. At first, it is clear that the respondents were convinced in the ease of use wearable devices could offer. The majority of respondents came up with a positive answer. Next to that, the share of negative answers is relatively seen very low; only 6 people were negative on this aspect. When looking at the other factors influencing technology acceptation, it is clear to see that the perceived usefulness, attitude towards using and intention to use are relatively positive. The majority of respondents answered positively towards these aspects and is therefore showing that they are willing to adopt this new technology. What must be noted for intention however is that respondents are clearly more positive towards wearables that can be used as a stand-alone device when compared to those that can only function as complementary device. This could possibly be caused by the associations people have with smart electronic devices. Currently most smart device can fulfill a wide variety of functions, which is reflected in the great availability of allin-one devices like consoles, computers, laptops, tablets and even hybrid devices.

When looking at this data, it is very clear that a small share of the respondents is currently using a wearable device. Only $16 \%$ states that they use wearables. Within this sample, no dominant group can be identified since there is no device category that has been represented more than the others. When comparing this adoption rate with the estimations by Business Insider [30] and CCS Insight [10], some similarities come to mind.

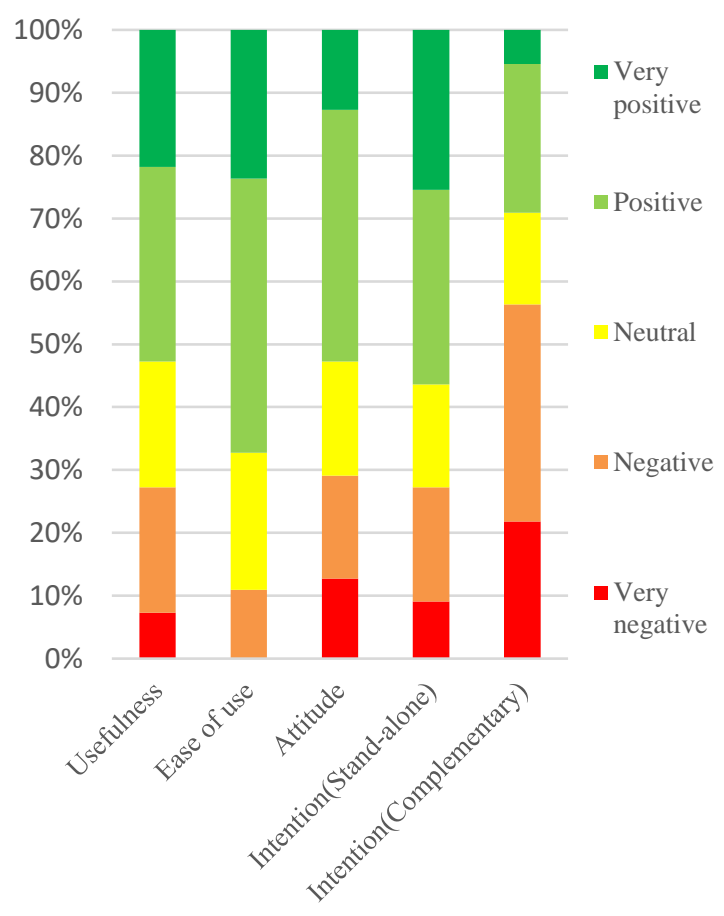

Fig. 4: TAM analysis on wearables.

Both Business Insider and CCS Insight claim that the current adoption rate of wearable devices still has a lot to grow before reaching it's potential $[10,30]$. BI states that in 2015, a total of 33 million wearable devices will ship. This should grow to 148 million in 2019 [30]. CCS Insight published market data which are somewhat comparable [10]. 
According to them, shipments of smart wearables are expected to grow from 22 million in 2014 to 135 million in 2018.

When looking at the data gained from the questionnaire this data gets somewhat confirmed. The results show that respondents in general have a positive opinion on wearable devices and are convinced in the ease of use and usefulness these wearables can offer. Next to that, the majority of people claim they have the intention to use wearable devices in the future. What has to be noted however is that this applies for wearables which can be used as a stand-alone device. The questionnaire has shown that people are not so eager to adopt complementary wearable devices. Lastly, the attitude towards using wearables is also predominantly positive.

The current usage rate might be low, but when looking at the results, the breakthrough point has been reached. Next to that, Roger's diffusion of innovation curve shows that diffusion of innovations gets faster over time in the first stages of the product life cycle. Considering the current usage rate and the market acceptation of wearable devices, it is likely that the wearable industry will grow rapidly in the short-term.

\subsection{Perceived feature importance}

The previous sections have shown that people are willing to adopt wearable devices. People are confident in the wearable product category. The majority of respondents accepts the technology, this shows the good market potential, which is available for these devices. The current usage rate might be low, but this data promises a bright future for this industry.

Within the questionnaire research, respondents have also been asked which features are most important for wearable devices in their opinion. The most important categories have been chosen, based on the performance of these apps on smartphones. The added value wearables can offer for these various functions have been shown and outlined thoroughly within the questionnaire. These questions were asked based on a Likert scale from 1-5 in which 1 represents 'not important at all' and 5 'very important' The results from these questions are shown in figure 5.

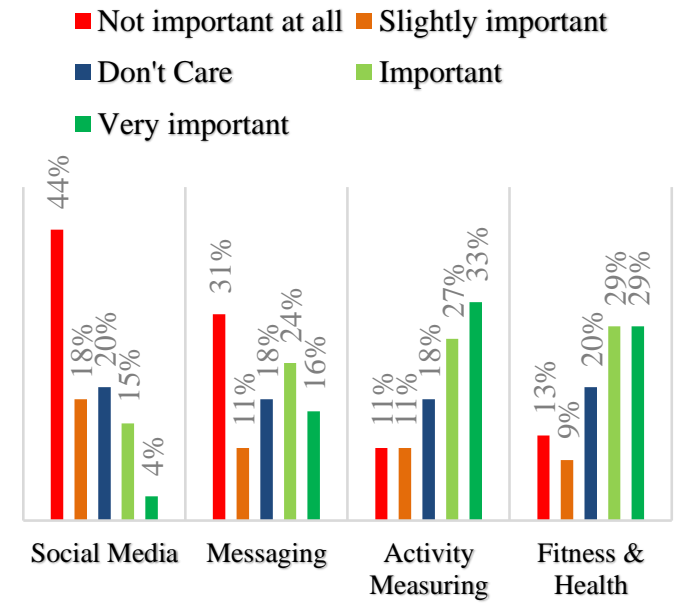

Fig. 5: Important features of wearables.

This graph shows the most important functions for wearable devices and how their importance is perceived in the minds of potential customers. What is clear is that potential customers do not perceive social media functions important. The majority of respondents stated that these functions are not important if they were looking to buy a wearable. This is somewhat surprising because social media has grown enormously as a consequence of the mobilization of devices. Apps like Twitter \& Facebook are the most popular ones on the different app stores, according to their data. Messaging functions are a more doubtful category. The responses do not show a clear image. $31 \%$ of respondents claim that these functions are not important at all. On the other hand, $40 \%$ of respondents think these functions are at least important.

When looking at Activity measuring and Fitness \& Health functionality, the opinion of respondents is very clearly shifted to the positive side. Respondents think these functions are absolutely important and would be the main functionalities people are looking for in wearable devices. This can partly be explained by the enormous popularity of these apps for smartphones. It can also be explained by the additional functionalities wearable devices can offer. This is supported by [11], who state that wearable devices can perform many of the same computing tasks as mobile phones and laptop computers; however, in some cases, wearable technology can outperform these hand-held devices entirely. Wearable technology tends to be more sophisticated than hand-held technology on the market today because it can provide sensory and scanning features not typically seen in mobile and laptop devices, such as biofeedback and tracking of physiological function. These functions are most applicable for activity tracking and fitness \& health functionality.

Following from the literature study, in the questionnaire functions were asked that are perceived as most important by respondents. These questions asked are based on the Kano model. The Kano Model of Customer Satisfaction 
classifies product attributes based on how they are perceived by customers and their effect on customer satisfaction [27]. The results from the questionnaire research conducted have been categorized according to the Kano Model. The results are presented in figure 6 below.

This graph clearly shows that there is a lot of confusion present among respondents. The high amount of responses that led to an indifferent classification shows that respondents did not really know which aspects are good and bad in wearable devices. This is highlighted by the high amount of responses that led to an invalid categorization. For those who did know what to look for in wearables, the unimportance of achievement sharing is notable. This may incorporate the fact that people are not willing to share their personal data with relatives.

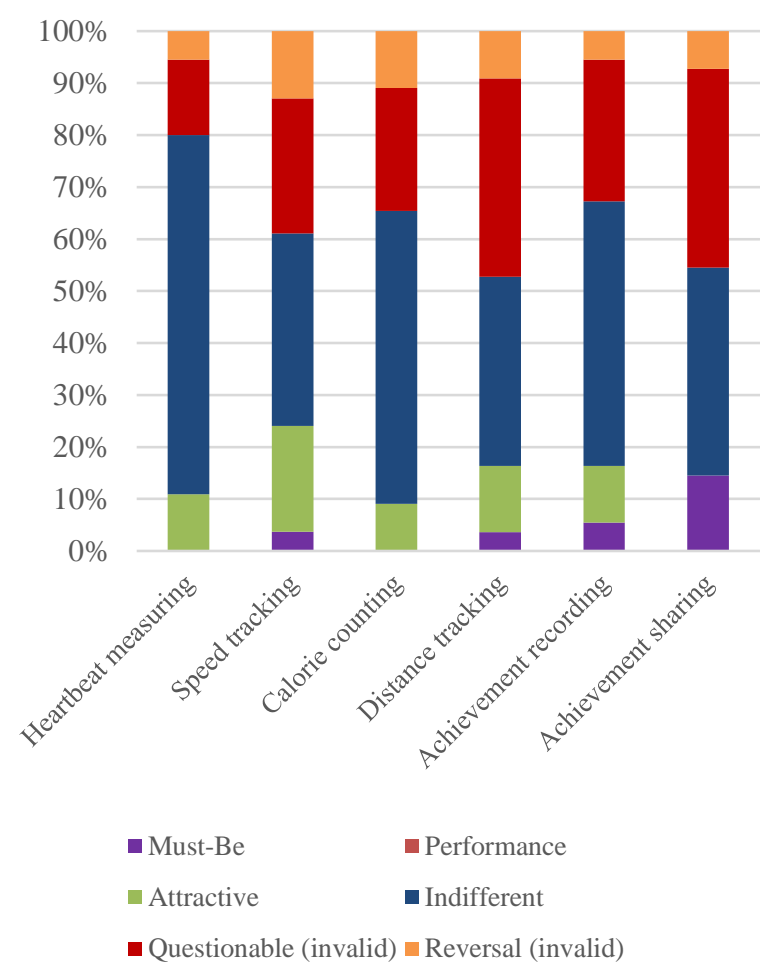

Fig. 6: Important features of gamified health apps.

\section{Analysis \& Implications}

What we see very clearly in section 3.1 is that respondents to the interview have a positive opinion on the relevance of gamification for improving their personal health. Next to that, respondents are confident in the userfriendliness of gamification. The attitude towards gamification is predominantly positive and this has a great effect on the willingness of people to use gamification in their everyday life. Also, the responses to the interviews have shown that people have a lot of confidence in the usefulness and user-friendliness of gamification. These results correspond with conducted questionnaire research (cf. figure 1) and existing literature like [3, 31], who describe the different factors that led to recent successes of gamified health apps.

When asked about the usage of fitness and running apps, the response is more two-sided. There is however a majority that is using these apps or have the intention to use them on the short term. This shows that although fitness apps have been adopted widely, they did not yet reach their full market potential. When analyzing this data with Diffusion of Innovations and the Product Life Cycle in mind, gamified health apps can be placed in the phase of the late early majority. This incorporates the fact that gamified health apps are adopted and accepted by approximately half of the population, which are characterized by their high propensity towards innovations. The rest of the population, who are generally far more conservative, still haven't adopted these games however.

The positive perception of usefulness and userfriendliness shows however that health gamification has overcome the breakthrough point and will probably grow very fast in the short term. With this knowledge, it is interesting to look at the side effects this causes for the wearable industry.

When comparing this data to the data on wearable devices gathered by the questionnaire, some similarities arise. Respondents are also predominantly positive towards wearable devices and most importantly appreciate the usefulness and ease of use these devices can offer. These similarities in people's mindset may lead to a situation in which wearables and gamification can function as complementary technologies, which are strengthening each other

This gets confirmed by questionnaire data (cf. figure 5). This data shows that people are far more interested in activity measuring and fitness \& health functionalities when compared to other popular features like messaging and social media.

The data gathered by the questionnaire shows the willingness of respondents to adopt wearables as new products. As stated before, the main factor for this is the usefulness and ease of use wearable devices can offer. Respondents perceive these factors as very positive and are therefore likely to accept this technology. When looking at the other factors influencing technology acceptation, it is clear to see that the attitude towards using and intention to use are perceived more doubtful but still relatively positive.

What these results mainly show is that wearable devices have not yet been accepted and adopted up to a degree that gamification has already achieved. This is also reflected in the current usage rate of both technologies. The current usage rate might be low, but when looking at the TAMmodel in combination with Diffusion of Innovations and the PLC, it is likely that the breakthrough point has been approached. 
What can be concluded from the data gathered by the interviews and questionnaire combined is that although gamification and wearable devices are alike in most parts of the TAM analysis, they mainly differ when looking at the current adoption rate and the intention to use them in the short term. Gamification is clearly ahead of wearables and the combination can therefore function as the killer feature for these devices.

To find out which gamification functionality is the main reason why people are looking to buy wearable devices, the Kano-model based questionnaire comes in useful. This model identifies various product characteristics based on customer perception by a specific framing of questions. What the data gathered by this survey research shows is that activity measuring and fitness \& health applications are clearly perceived as most important. At the same time however, this analysis shows that respondents do not really know which specific functions they are looking for. The answers often led to an answer classification of 'Indifferent', which means that respondents do not care whether this function is available on the wearable device. This is in line with the lack of confidence people have in the information quality health gamification can deliver. Results of this interview research have shown that respondents do think that gamification provides additional data, which might be valuable for activity tracking. At the same time they strongly doubt the quality of this information.

What is noteworthy about this finding is that although people have strong doubts about the information quality of gamified health apps and the features within wearables that add value to them, respondents still think that wearables are useful and easy to use. Considering these facts and the customer's perception derived from the TAM-analysis, as well as the current usage rate and the it is likely that the wearable industry will grow rapidly in the short-term. This can be clarified by referring to diffusion of Innovations [25] and the Product Life Cycle [26] which show that adoption of innovations gets faster over time in the first stages of the product life cycle. This finding supports the statements of business intelligence institutes like BI and CCS Insight [10, 30]. It is likely that in the beginning, potential customers will be adopting wearables merely for the reason of eagerness.

\section{Conclusions}

Can gamification help with the adoption of wearables for a healthy lifestyle? Seeking to answer this question we used a multi-method approach in this study and applied a technological and consumer market perspective to analyze data from 40 interviews with residents of the Netherlands and Germany and an online survey among 56 participants.

We learned that wearables are a booming device category. Today manufacturers of wearables heavily focus on their devices health monitoring capabilities and the promotion of healthy lifestyles. However, so far it is unclear whether consumers perceive this kind of functionality most important for wearables. In this paper we analyzed people's attitudes towards the adoption of wearables for a healthy lifestyle and elicited features consumers are looking for in wearables. Based on the results of our online survey, activity tracking and fitness \& health functionality are perceived as most important by (potential) consumers. The results, however, also stress that although respondents are convinced that activity tracking and fitness \& health functionality are crucial features of wearables, they do not yet know exactly what they are looking for in wearables. As such, it is likely that people who are currently looking to buy a wearable device are mainly curious towards this emerging device category and see it as a must-have, without having any specific function for it in mind. A potential explanation for this might be wide variety of currently available wearable devices, ranging from smart watches to fitness bracelets and smart glasses. There is no standard specification for wearables whatsoever and functionalities vary greatly. We think that this is mainly caused by the infancy of the wearables industry and that this will probably fade out over time, once manufacturers and consumers themselves better understand consumer's requirements for wearables.

In the meantime gamification might help to drive the adoption of wearables for healthy lifestyles. As the results of our interviews and online survey indicate, current and potential consumers perceive gamified health apps positive. This is mainly due to the fact that these kinds of apps are generally considered useful and user-friendly, which leads to an overall positive attitude. Accordingly, about half of the respondents in our study are currently using one or more gamified health apps, whereas another quarter is willing to use such applications in the short term. In general, people who currently do not use gamified health apps are inclined to do so in the short term, according to our survey. Adding to this, the current adoption rate and consumer perceptions are characteristic for a market phase in which fast growth is normally achieved. It thus seems likely that substantial market growth for gamified health apps can be achieved in the short term. This opens up new possibilities for related industries, which are able to join this success (e.g., wearables). As such, gamification can provide consumers with motivating and enticing interaction concepts for wearables, thus realizing synergies in the promotion of healthy lifestyles.

Notwithstanding the positive attitudes towards wearables and gamified health apps in general, adoption and usage rates of wearables are still relatively low. Yet, consumer's perceptions of wearables are slowly but steadily becoming more positive. People's interest in wearables is high and perceived usefulness and user-friendliness are positive. Adding to this, our results show that although consumers think gamified health apps provide useful physical data, they also have doubts over data quality. For a large portion of surveyed consumers the quality of information provided by gamified health apps and wearables is not convincing at all. Practically, we contribute by showing industry that they 
should add relevance to the wearables and that can be done with gamification. Theoretically we contribute in prioritizing functionalities and combining both concepts as mutually beneficial.

Clearly the small sample size of only 56 participants and the focus on the Netherlands and Germany are limitations of our research. However, due to extensive interviews we were able to substantiate our insights from the online survey with rich qualitative data and are confident that our results hold true. Nonetheless, future research should further investigate the effects of the combination of wearables with gamified health apps. In particular additional studies with larger sample sizes and nationals from other parts of the world need to be conducted. Moreover, additional research is needed to elicit consumers' requirements for wearables and gamified health apps in terms of functionality and data quality.

Based on the results of this study we are confident that consumers' positive attitudes towards wearables and gamified health apps, together with an improved information quality and the development of a dominant design can highly contribute to healthier lifestyles worldwide in the near future.

\section{References}

[1] Snabe, J.H. Keynote European Conference on Information Systems 2016 (Istanbul, Turkey, 2016/06/12-15).

[2] World Health Organization Global status report on noncommunicable diseases.

http://apps.who.int/iris/bitstream/10665/148114/1/9789241564854 _eng.pdf (retrieved 2016/03/17).

[3] West, J.H., Hall, P.C., Hanson, C.L., Barnes, M.D., GiraudCarrier, C. and Barrett, J. There's an app for that: content analysis of paid health and fitness apps. Journal of Medical Internet Research, 14, 3 e72.

[4] Cisco Cisco Visual Networking Index: Global Mobile Data Traffic Forecast Update, 2015-2020 White Paper.

http://www.cisco.com/c/en/us/solutions/service-provider/visualnetworking-index-vni/index.html - mobilevni (retrieved 2015/04/20).

[5] Deterding, S., Dixon, D., Khaled, R. and Nacke, L., From game design elements to gamefulness: defining gamification. In Proceedings of the 15th International Academic MindTrek Conference: Envisioning Future Media Environments (Tampere, Finland, 2011/09/28-30) 9-15.

[6] Elias, P., Rajan, N.O., McArthur, K. and Dacso, C.C. InSpire to promote lung assessment in youth: evolving the selfmanagement paradigms of young people with asthma. Medicine 2.0, 2, $1 \mathrm{e} 1$.

[7] Yoganathan, D. and Kajanan, S., Persuasive Technology for Smartphone Fitness Apps. In Pacific Asia Conference on Information Systems (Jeju Island, Korea, 2013/06/18-22) 185.

[8] Liu, C., Zhu, Q., Holroyd, K.A. and Seng, E.K. Status and trends of mobile-health applications for iOS devices: A developer's perspective. Journal of Systems and Software, 84, 11 2022-2033.
[9] Davis, F.D. Perceived usefulness, perceived ease of use, and user acceptance of information technology. MIS Quarterly, 13, 3 319-340.

[10] Deacon, H. and Koytcheva, M. Smartwatches and Smart Bands Dominate Fast-Growing Wearables Market. http://www.ccsinsight.com/press/company-news/1944smartwatches-and-smart-bands-dominate-fast-growing-wearablesmarket (retrieved 2015/04/20).

[11] Tehrani, K. and Andrew, M. Wearable Technology and Wearable Devices: Everything You Need to Know. http://www.wearabledevices.com/what-is-a-wearable-device/ (retrieved 2015/04/20).

[12] Pyattaev, A., Johnsson, K., Andreev, S. and Koucheryavy, Y. Communication challenges in high-density deployments of wearable wireless devices. IEEE Wireless Communications, 22, 1 12-18.

[13] Rawassizadeh, R., Price, B.A. and Petre, M. Wearables: Has the age of smartwatches finally arrived? Communications of the ACM, 58, 1 45-47.

[14] Butte, N.F., Ekelund, U. and Westerterp, K.R. Assessing physical activity using wearable monitors: measures of physical activity. Medicine \& Science in Sports \& Exercise, 44, 1 Suppl 1 S5-12.

[15] McKeown, S., Krause, C., Shergill, M., Siu, A. and Sweet, D. Gamification as a strategy to engage and motivate clinicians to improve care. Healthcare Management Forum, 29, 2 67-73.

[16] Maturo, A. and Setiffi, F. The gamification of risk: how health apps foster self-confidence and why this is not enough. Health, Risk \& Society, 17, 7-8 1-18.

[17] Dithmer, M., Rasmussen, J.O., Grönvall, E., Spindler, H., Hansen, J., Nielsen, G., Sørensen, S.B. and Dinesen, B. "The Heart Game": Using Gamification as Part of a Telerehabilitation Program for Heart Patients. Games for Health Journal, 5, 1 27-33.

[18] Montola, M., Stenros, J. and Waern, A. Pervasive games: theory and design. Morgan Kaufmann Publishers Inc., San Francisco, USA, 2009.

[19] Zichermann, G. and Cunningham, C. Gamification by design: Implementing game mechanics in web and mobile apps. O'Reilly Media, Inc., Sebastopol USA, 2011.

[20] Thiebes, S., Lins, S. and Basten, D., Gamifying Information Systems-A Synthesis of Gamification Mechanics and Dynamics. In European Conference on Information Systems (Tel Aviv, Israel, 2014/06/09-11).

[21] Hunicke, R., LeBlanc, M. and Zubek, R., MDA: A formal approach to game design and game research. In Proceedings of the AAAI Workshop on Challenges in Game AI (San Jose, USA, 2004/07/25-29) 1 .

[22] Hamari, J. and Koivisto, J. "Working out for likes": An empirical study on social influence in exercise gamification. Computers in Human Behavior, 50, September 2015 333-347.

[23] Michel-Verkerke, M. and Spil, T. The USE IT-adoptionmodel to predict and evaluate adoption of information and communication technology in healthcare. Methods of Information in Medicine, 52, 6 475-483.

[24] Miles, M.B. and Huberman, A.M. Qualitative data analysis: An expanded sourcebook. Sage, Thousand Oaks, USA, 1994. 
[25] Rogers, E.M. Diffusion of innovations. Simon and Schuster, New York City, USA, 2010.

[26] Vernon, R. The product cycle hypothesis in a new international environment. Oxford bulletin of economics and statistics, 41, 4 255-267.

[27] Sauerwein, E., Bailom, F., Matzler, K. and Hinterhuber, H.H., The Kano model: How to delight your customers. In International Working Seminar on Production Economics (Innsbruck, Austria, 1996/02/19-23) 313-327.

[28] Khalaf, S. Health and Fitness Apps Finally Take Off, Fueled by Fitness Fanatics.

http://flurrymobile.tumblr.com/post/115192181465/health-andfitness-apps-finally-take-off-fueled (retrieved 2015/04/20).

\begin{tabular}{|c|}
\hline Do you own a smartphone? \\
\hline $\begin{array}{l}\text { Are you, or are you willing to use a health app like Nike+ (or RunKeeper, } \\
\text { Strava, etc.) }\end{array}$ \\
\hline Which app specific functions are crucial in your opinion \\
\hline In which sports are you currently engaged? \\
\hline Why are you using fitness apps? (Please check the 3 most important reasons) \\
\hline Which devices are you currently using to keep track of your activity? \\
\hline How frequently are you using activity-tracking devices on average? \\
\hline Would you be interested in buying a wearable device? \\
\hline $\begin{array}{l}\text { If you were interested in buying a wearable device, would you have } \\
\text { preference towards one from the same company as your smartphone? }\end{array}$ \\
\hline Are you currently using a wearable device? If yes, which? \\
\hline $\begin{array}{l}\text { How important are social media functions for wearable devices in your } \\
\text { opinion? }\end{array}$ \\
\hline $\begin{array}{l}\text { How important are messaging functions for wearable devices in your } \\
\text { opinion? }\end{array}$ \\
\hline $\begin{array}{l}\text { How important are activity-measuring functions for wearable devices in your } \\
\text { opinion? }\end{array}$ \\
\hline $\begin{array}{l}\text { How important are fitness \& health functions for wearable devices in your } \\
\text { opinion? }\end{array}$ \\
\hline If you have any remarks or explanations you can leave them here \\
\hline $\begin{array}{l}\text { How important is heartbeat measuring functionality for wearable devices in } \\
\text { your opinion? }\end{array}$ \\
\hline $\begin{array}{l}\text { How important is speed tracking functionality for wearable devices in your } \\
\text { opinion? }\end{array}$ \\
\hline $\begin{array}{l}\text { How important is calorie counting functionality for wearable devices in your } \\
\text { opinion? }\end{array}$ \\
\hline $\begin{array}{l}\text { How important is distance tracking functionality for wearable devices in your } \\
\text { opinion? }\end{array}$ \\
\hline $\begin{array}{l}\text { How important is achievement recording functionality for wearable devices } \\
\text { in your opinion? }\end{array}$ \\
\hline How important is the possibility of sharing achievements in your opinion? \\
\hline $\begin{array}{l}\text { If you have any remarks on the questions asked above, let it know in this text } \\
\text { box. }\end{array}$ \\
\hline will provide added val \\
\hline
\end{tabular}

[29] Barnes, K., Connolly, C., Tsouderos, T., Comer, B., ett, S.H., Cholera, U. and O'Neal, J. Healt wearables: Early days.

https://www.pwc.com/us/en/health-industries/top-health-industryissues/assets/pwc-hri-wearable-devices.pdf (retrieved 2016/06/10).

[30] Danova, T. The Wearable Computing Market Report: Growth Trends, Consumer Attitudes And Why Smartwatches Will Dominate. Business Insider Intelligence 2014.

[31] Zyda, M. From visual simulation to virtual reality to games. Computer, 38, 9 25-32.

\section{APPENDIX Questionnaire adapted from [27]}

\begin{tabular}{|c|c|}
\hline & Do you expect wearables will be easy to use and user-friendly? \\
\hline & Do you want to use a wearable as a stand-alone device? \\
\hline & Do you want to use a wearable as a complementary device? \\
\hline & $\begin{array}{l}\text { Would you be willing to wear a wearable device the entire day, even during } \\
\text { sleep? }\end{array}$ \\
\hline & How often per week are you willing to use wearable devices? \\
\hline & $\begin{array}{l}\text { Would you be willing to share your data gained from the wearable device } \\
\text { with the developers to provide better feedback? }\end{array}$ \\
\hline & $\begin{array}{l}\text { If you have any remarks on the questions asked above, let it know in this text } \\
\text { box. }\end{array}$ \\
\hline & $\begin{array}{l}\text { Would it be a problem for you if social media functions were lacking for } \\
\text { wearable devices? (Facebook/Twitter/Instagram etc.) }\end{array}$ \\
\hline & $\begin{array}{l}\text { Would it be a problem for you if activity-measuring functions were lacking } \\
\text { in wearable devices? }\end{array}$ \\
\hline & $\begin{array}{l}\text { Would it be a problem for you if fitness \& health functions were lacking in } \\
\text { wearable devices? }\end{array}$ \\
\hline & $\begin{array}{l}\text { Would it be a problem for you if messaging functions were lacking in } \\
\text { wearable devices? }\end{array}$ \\
\hline & $\begin{array}{l}\text { Would it be a problem if wearable devices were not capable of capturing your } \\
\text { heartbeat? }\end{array}$ \\
\hline & $\begin{array}{l}\text { Would it be a problem if wearable devices were not capable of tracking your } \\
\text { speed while working out? }\end{array}$ \\
\hline & $\begin{array}{l}\text { Would it be a problem if wearable devices were not able to track the calories } \\
\text { you burned while working out? }\end{array}$ \\
\hline & $\begin{array}{l}\text { Would it be a problem if wearable devices were not able to track the covered } \\
\text { distance of your workout? }\end{array}$ \\
\hline & $\begin{array}{l}\text { Would it be a problem if wearables were not capable of recording the } \\
\text { achievements you reached? }\end{array}$ \\
\hline & $\begin{array}{l}\text { Would it be a problem if achievement-sharing functionality lacks on } \\
\text { wearable devices? }\end{array}$ \\
\hline & $\begin{array}{l}\text { Would it be a problem for you if a wearable device cannot be used without } \\
\text { carrying a smartphone? }\end{array}$ \\
\hline & $\begin{array}{l}\text { Would it be a problem for you to wear a wearable device the entire day, even } \\
\text { during sleep? }\end{array}$ \\
\hline & $\begin{array}{l}\text { Would it be a problem if data gained from the wearable device would be } \\
\text { shared to provide better feedback? }\end{array}$ \\
\hline
\end{tabular}

